\title{
FASILITAS OLAHRAGA INTERAKTIF DI RAWA BUNGA
}

\author{
Jessica $^{1)}$ \\ 1)Program Studi S1 Arsitektur, Fakultas Teknik, Universitas Tarumanagara, jessicajong10@gmail.com
}

\begin{abstract}
Abstrak
Kelurahan Rawa Bunga memiliki jumlah penduduk yang selalu meningkat seiring berjalannya waktu. Peningkatan jumlah penduduk yang terjadi berdampak kepada perubahan fungsi lahan yang tidak semestinya seperti Rancangan zonasi awal yang mempunyai komposisi yang seimbang antara komersial dan hunian. Tetapi pada kenyataannya, fungsi lahan yang ada didominasi oleh hunian. Walaupun fungsi hunian bertambah, tetapi tidak diiringi pertambahan third place yang memadai. Akibatnya adalah masalah beruntun berupa kebutuhan dasar manusia yang tidak terpenuhi. Dampak yang dihasilkan adalah pelaksanaan aktivitas masyarakat di tempat - tempat yang tidak semestinya sebagai ganti fasilitas lingkungan yang tidak memadai. Tujuan dari perancangan ini adalah berusaha memenuhi kebutuhan dasar masyarakat di Kelurahan Rawa Bunga akan aktivitas penunjang seperti sosialisasi dan interaksi baik antar manusia maupun dengan lingkungannya melalui third place. Metode Perancangan yang dipakai dibagi menjadi dua tahap, pertama tahap pencarian data dengan metode empiris yaitu observasi, studi kota dan analisis. Tahap kedua, Tahap perancangan dimulai dari hasil yang didapat dari analisis berupa program. Program akan diolah dengan pendekatan metode desain tipologi kegiatan. Ide dari perancangan ini adalah fasilitas lingkungan atau third place dengan aktivitas olahraga yang memakai teknologi interaktif untuk membantu proses sosialisasi dan interaksi baik antar manusia maupun dengan lingkungannya. Olahraga dipilih karena masyarakat di Rawa Bunga senang dengan aktivitas yang bersifat olahraga dan tidak lupa juga disisipi elemen kebudayaan Betawi untuk memperkenalkan genius loci kawasan Rawa Bunga.
\end{abstract}

\section{Kata kunci: olahraga interaktif; Rawa Bunga; Third Place}

\begin{abstract}
Rawa Bunga population is constantly increased as time goes by. The increasing population in Rawa Bunga is leading to a change in land-use planning. The initial planning which create a balance between commercial and housing is forced to change into domination of housing. Although the housing community is constantly increased, but the government didn't increased the community facility or third place in Rawa Bunga. This condition is causing a huge problem for the community to satisfy their daily basic needs. Even more, they started to occupy every vacant place for their activity and making problems for other people. The objective of this design is making a third place for the community of Rawa Bunga that can help them to socialize and interact with each other. The design method is divided into two parts, the first part is collecting data from observation, urban study, and analysis. The second part is start from the program and follow the theory of activity tipology. The design idea is a community facility or third place for interactive sport, sport and interactive technology is chosen because the community in Rawa Bunga loves sports. In addition, the third place will inserted by Betawi culture to introduce the genius loci of Rawa Bunga.
\end{abstract}

Keywords: interactive sports; Rawa Bunga; Third Place 


\section{PENDAHULUAN}

\section{Latar Belakang}

Jakarta adalah kota metropolitan yang memiliki jumlah penduduk paling besar di Indonesia. Pertumbuhan penduduk yang terus meningkat akan diiringi oleh pertumbuhan permintaan akan kebutuhan dasar manusia. Menurut teori yang dikemukakan oleh Maslow yaitu "Maslow's hierarchy of needs". Manusia pada hakikatnya membutuhkan beberapa aspek yang harus dipenuhi untuk mempertahankan keberlangsungan hidupnya dengan cara aktivitas aktivitas seperti hiburan, sosialisasi, dan aktivitas keseharian lainnya. Aktivitas tersebut membutuhkan wadah yang bisa dipakai manusia secara bebas sebagai fasilitas lingkungan. Dalam hal ini, third place adalah wadah arsitektur yang dapat dirancang secara khusus untuk memenuhi kebutuhan dasar manusia. Namun, kenyataannya third place yang ada di Jakarta sebagian besar berupa shopping mall, dan tempat-tempat yang bersifat komersial yang hanya memenuhi aspek physiological needs, dan safety needs. Keadaan ini menyebabkan beberapa kebutuhan dasar manusia tidak terpenuhi secara ideal di kota Jakarta pada saat ini, salah satu nya adalah Kelurahan Rawa Bunga. Kelurahan Rawa Bunga adalah sebuah Kelurahan padat penduduk di kecamatan Jatinegara yang jumlah penduduknya selalu meningkat seiring berjalannya waktu. Peningkatan jumlah penduduk yang terjadi berdampak kepada perubahan fungsi lahan yang tidak semestinya.

Rancangan zonasi awal yang mempunyai komposisi yang seimbang antara komersial dan hunian. Tetapi pada kenyataannya, fungsi lahan yang ada didominasi oleh hunian. Walaupun fungsi hunian bertambah, tetapi tidak diiringi pertambahan third place yang memadai. Fenomena ini menyebabkan masalah beruntun berupa kebutuhan dasar manusia yang tidak terpenuhi. Hal ini berdampak pada masyarakat mengambil tempat yang tidak semestinya seperti bahu jalan dan tengah jalan untuk menjalankan aktivitas keseharian sebagai ganti fasilitas lingkungan yang tidak memadai. Selain itu, Kelurahan Rawa Bunga memiliki citra atau karakter kawasan (Jenius Loci) bertemakan kebudayaan Betawi yang ditandai dengan adanya Taman Benyamin Sueb. Maka dari itu, Kelurahan Rawa Bunga harus membuat fasilitas lingkungan atau third place yang bisa menampung aktivitas keseharian masyarakat untuk memenuhi kebutuhan dasar yang kurang. Pemilihan program - program yang tepat dan didukung teknologi interaktif diharapkan bisa meningkatkan kualitas hidup masyarakatnya dalam segi sosial serta mengimplementasikan unsur Betawi sebagai citra kawasan.

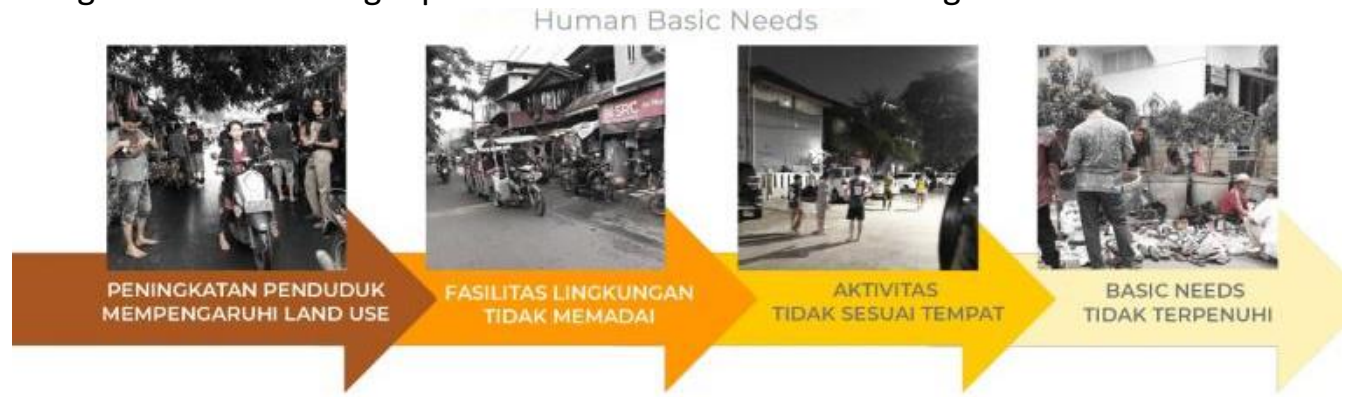

Gambar 1. Skema Permasalah Masyarakat Rawa Bunga Sumber: penulis, 2020

\section{Rumusan Permasalahan}

Perancangan ini merupakan pencarian jawaban dari masalah fasilitas lingkungan tidak memadai, aktivitas tidak sesuai tempat, dan basic needs tidak terpenuhi yang perlu diselesaikan di Rawa Bunga. Dimulai dari third place yang dapat memenuhi kebutuhan dasar masyarakat yang kurang di Kelurahan Rawa Bunga melalui aktivitas penunjang dan third place yang dapat mewadahi aktivitas masyarakat Kelurahan Rawa Bunga agar memiliki kualitas hidup yang lebih baik dan mempunyai citra Betawi yang aktif. 


\section{Tujuan}

Tujuan proyek ini adalah membuat third place yang dapat memenuhi kebutuhan dasar masyarakat di Kelurahan Rawa Bunga akan aktivitas penunjang dan menciptakan wadah untuk bersosialisasi dan beraktivitas sehari-hari masyarakat Kelurahan Rawa Bunga. Tidak lupa juga untuk mengakomodasi kegiatan warga di sekitar Kelurahan Rawa Bunga dan membuat kelurahan Rawa Bunga menjadi kawasan yang hidup dan mempunyai citra Betawi yang aktif.

\section{KAJIAN LITERATUR}

\section{The Great,Good Place}

Oldenburg mengatakan bahwa The Third Place merupakan tempat peralihan yang dibutuhkan oleh masyarakat. Third place memiliki posisi diantara first place dan second place. The Third Place juga merupakan sebuah tempat untuk memenuhi kebutuhan sosial masyarakat dengan cara berkumpul dan bersosialisasi. Dalam buku The Great, Good Place dituliskan karakteristik dan ciri khas dari Third Place, diantaranya; pertama, neutral ground berarti third place adalah tempat yang bersifat netral, dimana pengguna tidak memiliki kepemilikan dan kewajiban untuk tempat tersebut sehingga mereka bisa bebas datang dan pergi. Kedua, third place as leveler yang berarti third place mengutamakan sifat keterbukaan dan third place diharuskan datang menjadi wadah berinteraksi dan bersosialisasi semua orang tanpa mengenal perbedaan status dalam aktivitasnya. Ketiga, conversation is the main activity yang berarti aktivitas utama yang terjadi pada third place adalah kegiatan bertukar pikiran dan bersenda gurau. Proses bertukar pikiran diharapkan bisa menjadikan masyarakat lebih terbuka satu dengan yang lain. Keempat, accessibility and accommodation yang berarti third place dalam pengaplikasiannya bisa mengakomodasi kebutuhan dan keinginan masyarakat sekitarnya. Third Place juga harus menjadi tempat yang memiliki kemudahan akses dan dapat ditempati oleh semua orang. Kelima, the regulars yang berarti third places mempunyai pengguna yang beraktivitas di dalamnya, yaitu pengunjung tetap. Aktivitas yang dilakukan the regulars akan membentuk suasana dari third place dan akan mengundang pengunjung baru untuk datang. Third Place juga harus bisa membuat pengunjung baru yang datang merasa puas dan dihargai. Keenam, $a$ low profile yang berarti third place merupakan tempat yang ramah untuk lingkungannya dari segi aktivitas maupun segi penampilan. Tempat yang ramah untuk lingkungannya harus bisa menerima semua elemen yang di lingkungannya. Ketujuh, the mood is playful yang berarti mood yang terbentuk dari aktivitas yang terjadi di dalam third place adalah mood yang menyangkan. Segala hal yang ada dan terjadi di third place memiliki makna khusus untuk penggunanya. Terakhir, a home away from home yang berarti third place bisa menciptakan perasaan nyaman dan hangat seperti suasana yang di rumah. Pengguna third place akan mengalami mental healing dengan berada di third place (Oldenburg, 1999).

\section{A Theory of Human Motivation}

Maslow dalam bukunya mengatakan tentang "Maslow's Hierarchy of Needs". Teori ini membagi kebutuhan dasar manusia menjadi beberapa bagian dengan aspek - aspek yang berbeda, yaitu; Pertama, self actulization adalah kebutuhan akan membuktikan dan menunjukan dirinya kepada orang lain untuk mendapatkan pengakuan. Pada tahan ini, manusia melatih dirinya sendiri dengan potensi yang dimilikinya. Kedua, esteem adalah kebutuhan akan penghargaan berhubungan dengan ego seseorang. Keinginan seseorang untuk merasa dihargai dan dihormati lewat status, ketenaran, reputasi. Ketiga, love/belonging, kebutuhan akan kasih saying dan rasa memiliki termasuk keinginan untuk dibutuhkan oleh orang lain agar bisa dianggap sebagai bagian dari komunitas sosialnya. pemenuhan kebutuhan ini dalam bentuk persahabatan, memiliki pasangan dan keturunan, kebutuhan untuk dekat keluarga dan kebutuhan antar pribadi lainnya. Keempat, safety adalah kebutuhan akan rasa aman meliputi rasa aman fisik, stabilitas, ketergantungan, perlindungan dan kebebasan dari hal yang dapat mengancam seperti kriminalitas, perang, terorisme, penyakit, dan bencana 
alam. Terakhir, physiological, kebutuhan fisiologis adalah kebutuhan manusia yang berhubungan dengan tubuhnya berupa sandang, pangan, papan. Kebutuhan ini berupa makan, minum, dan bernaung. Manusia akan selalu berusaha untuk memenuhi kebutuhan fisiologis dalam setiap waktu. (Maslow, 1943)

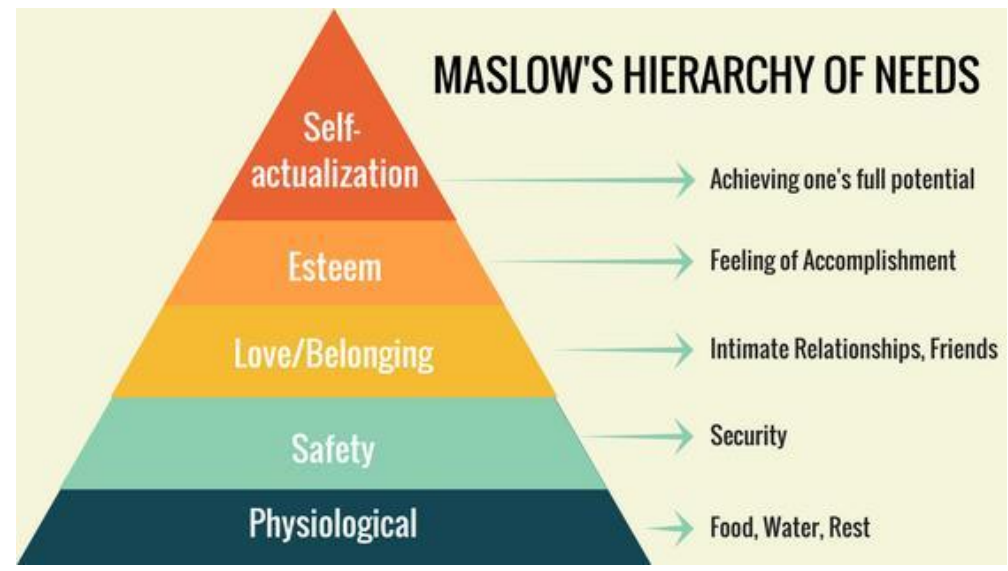

Gambar 2. Konsep Maslow's Hierarchy of Needs oleh Abraham Maslow Sumber: Maslow, A Theory of Human Motivation

\section{Architecture of Happiness}

De Botton dalam bukunya mengatakan tentang "Architecture of Happiness" bahwa arsitektur dapat mempengaruhi kebiasaan dan tingkat kebahagiaan seseorang baik secara langsung maupun tidak langsung. Poin-poin yang disampaikan di buku ini adalah; Pertama, Standar Arsitektural Berubah Seising Berjalannya Waktu, Perkembangan arsitektural selalu berkembang dari waktu ke waktu, perubahan tersebut dipengaruhi oleh trend yang berkembang di masyarakat contohnya trend teknologi, trend seni, dan lain - lain. Sesaat setelah terjadi perkembangan trend, definisi keindahan arsitektural juga berpindah mengikutinya. Tetapi ada satu prinsip yang tetap dipakai yaitu efisiensi. Seperti yang dikatakan arsitek Swiss-Francis Le Corbusier, efisiensi dan simplitas merupakan elemen dari keindahan arsitektural. Kedua, Arsitektur akan Berbicara dan akan Menggali Memori serta Mengingatkan, Arsitektur memiliki banyak jenis dan gaya yang sudah atau sedang berkembang, dan juga setiap orang memiliki prefrensi yang berbeda-beda atas setiap design. Hal tersebut dikarenakan memori seseorang akan suatu benda dan arsitektur itu sendiri. Oleh karena itu, bentuk dari suatu benda atau arsitektur dapat memberi kesan dan berbicara. Ketiga, Bangunan dapat Mengeluarkan aspek dari karakter manusia, manusia dapat dipengaruhi oleh kesan ruangan dimana tempat dia berada. Suasana ruangan dan kesan ruang dibutuhkan untuk mengeluarkan sifat atau kemampuan manusia ke tahap yang lebih maju. Seperti contohnya, orang kreatif akan membutuhkan tempat yang kreatif agar bisa mengeluarkan kemampuannya, dan juga orang beribadah yang membutuhkan suasana gereja agar bisa merasakan hadirat Tuhan secara seutuhnya. Keempat, Arsitektur dapat meningkatkan kualitas manusia, peningkatan kualitas dari dalam diri manusia bisa dipengaruhi oleh arsitektur. Menurut penelitian yang sudah dilakukan, orang-orang yang tinggal dalam suatu arsitektur yang mendukung akan mencerminkan diri mereka sesuai dengan tempat tinggal (De Botton, 2006).

\section{Interaktif}

Interaktif berasal dari kata interaksi, yaitu saling memberi aksi, berhubungan, dan mempengaruhi. Interaksi bisa terjadi dikarenakan terciptanya hubungan sebab akibat, berupa aksi dan reaksi sebagai penyeimbangnya. Warsita mengatakan bahwa interaktif adalah hal yang saling berkaitan dan mengkomunikasikan secara dua arah. Hal ini akan memberikan hubungan timbal balik yang saling bersesuaian dan saling menyeimbangkan. Pembelajaran 
interaktif biasanya menggunakan bantuan teknologi seperti komputer dan perangkat pendukung baik itu hardware maupun software. Pembelajaran secara interaktif bisa memaksimalkan pembelajaran lewat stimulus panca indra. Proses interaksi yang terjadi antar manusia, dan juga media dan manusia yang telah didesain untuk keperluan pendidikan (Warsita, 2008).

\section{METODE}

\section{Tahap Mencari dan Analisis Data}

Metode yang dipakai dalam mencari data adalah empirisme yang dibantu dengan observasi langsung di lapangan. Metode empiris mengacu kepada pengalaman manusia sebagai data utama, dan observasi langsung akan membantu memahami pengalaman manusia khususnya kebiasaan dan masalah - masalah lingkungan dari sudut pandang orang ketiga. Data yang telah didapat berupa masalah dan kebiasaan di lingkungan tersebut akan dianalisis menggunakan teori arsitektur sebagai acuan dalam memproses data secara lebih spesifik. Kesimpulan atau inti sari akan berupa program dan kegiatan.

\section{Tahap Perancangan}

Kesimpulan dan Intisari analisis tersebut akan diproses lebih lanjut melalui perancangan arsitektur. Dalam hal tersebut, metode yang digunakan adalah Metode Tipologi yang menitikberatkan kepada tipologi kegiatan. Merancang berdasarkan kegiatan akan membantu dalam merancang arsitektur secara kreatif dan unik karena tidak terperangkap kepada nama ruang dan tipologinya.

\section{DISKUSI DAN HASIL}

\section{Analisa Perancangan}

Berdasarkan metode yang digunakan, pertama mencari dan memproses data yang didapat lewat proses observasi. Proses observasi tersebut dilakukan di kelurahan Rawa Bunga, Jatinegara. Selama proses observasi berlangsung, dipilih juga tapak yang sekiranya menjadi tempat paling efektif untuk membuat third place yang dapat menyelesaikan masalah masalah yang berlangsung di Rawa Bunga dan juga memenuhi kebutuhan masyarakat Rawa Bunga. Tapak yang dipilih terletak di areal pemukiman agar bisa lebih dikhususkan untuk fasilitas masyarakat Rawa Bunga, dan juga penempatan tapak yang berada di tengah - tengah kelurahan akan memaksimalkan jangkauan ke seluruh sudut kelurahan Rawa Bunga.

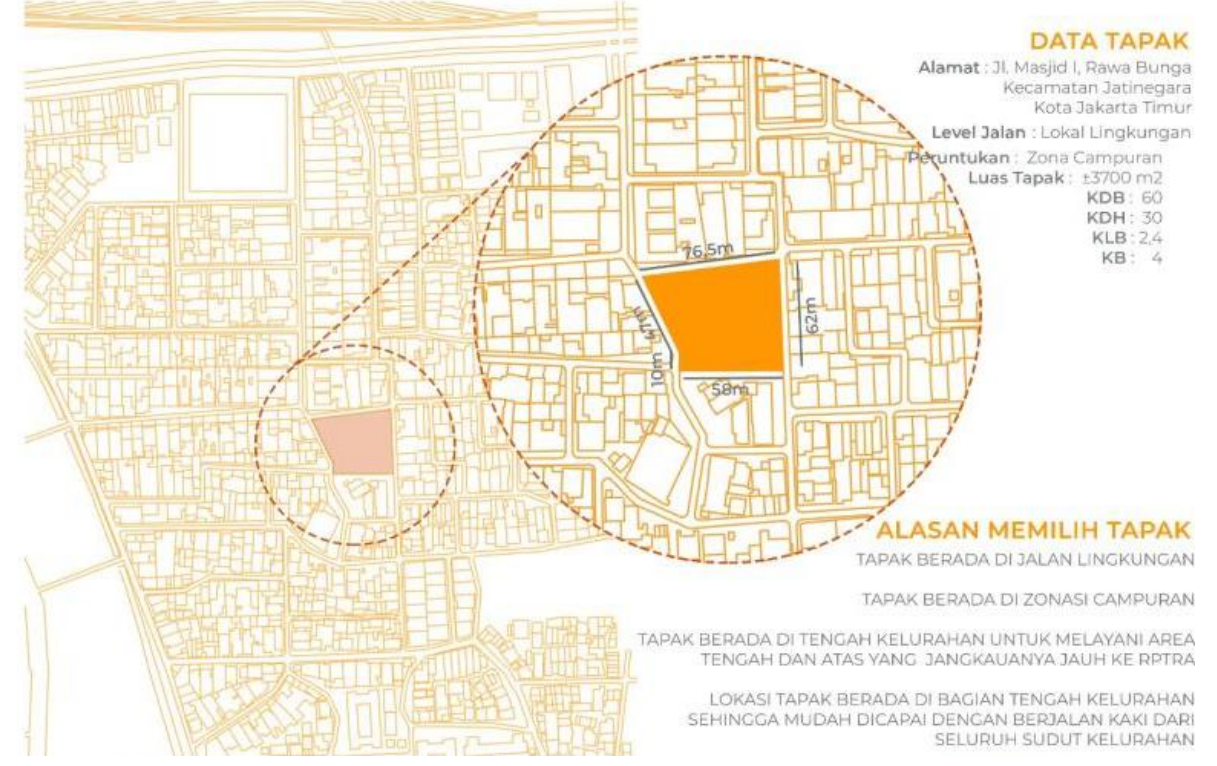

Gambar 3. Data Lokasi dan Keterangan Tapak Terpilih Sumber: penulis, 2020 
Hasil dari analisa data observasi dan studi kota Rawa Bunga juga memperlihatkan karakteristik dan kebiasaan masyarakat di Rawa Bunga yang menggemari kegiatan bermain, olahraga, dan bersosialisasi dengan sesama. Semua kegiatan tersebut bisa dijadikan pengikat hubungan dari masyarakat dan third place yang dibuat mengambil kegiatan bermain dan olahraga sebagai tema utama.

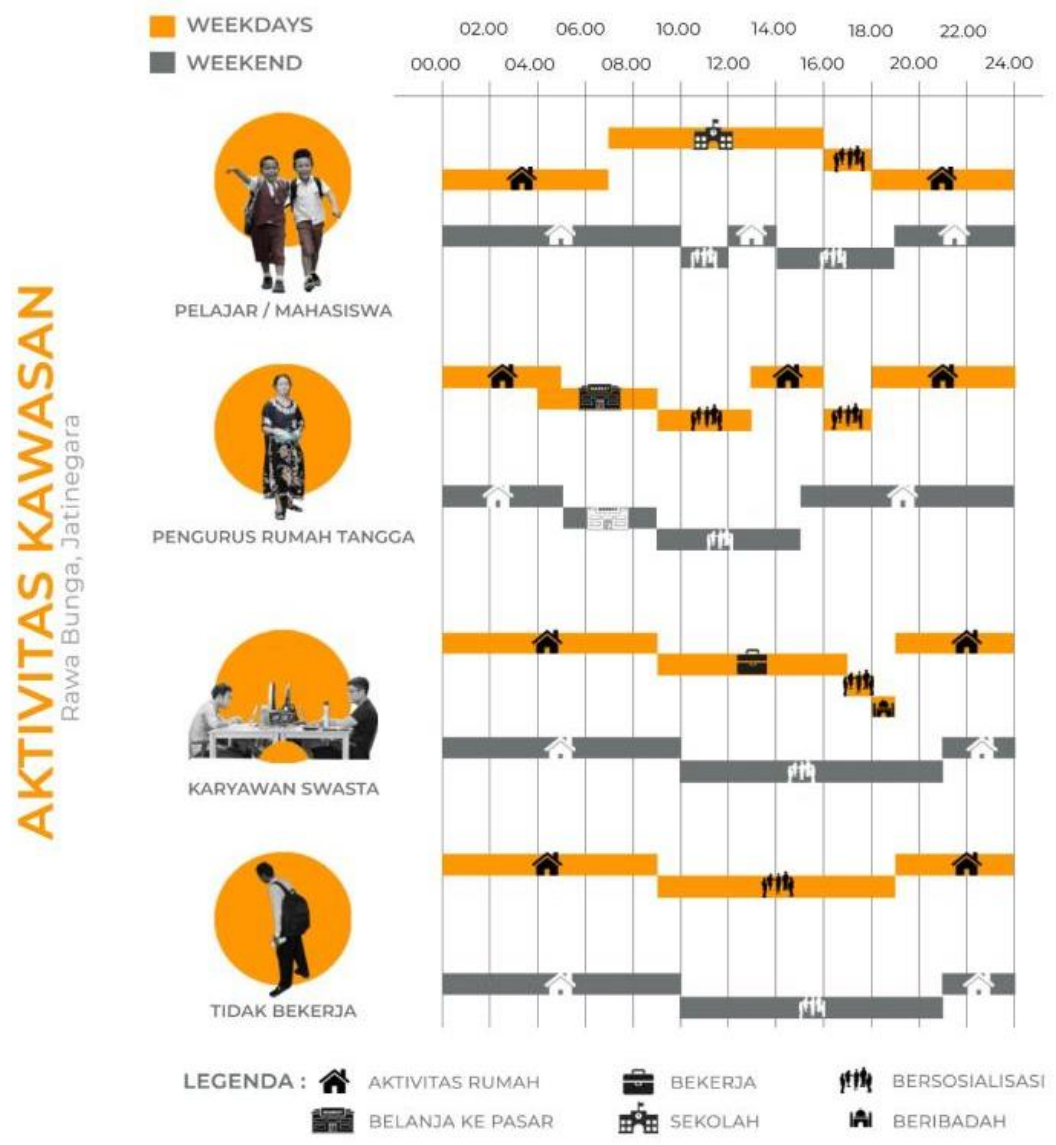

\section{AKTIVITAS DOMINAN}

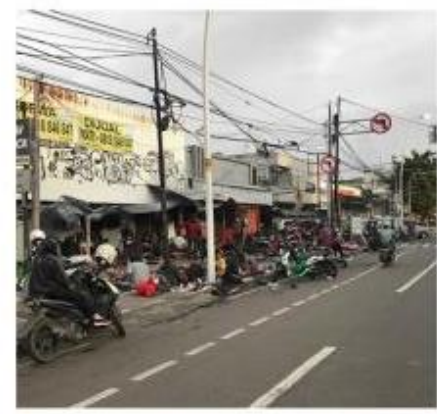

BERSOSIALISASI

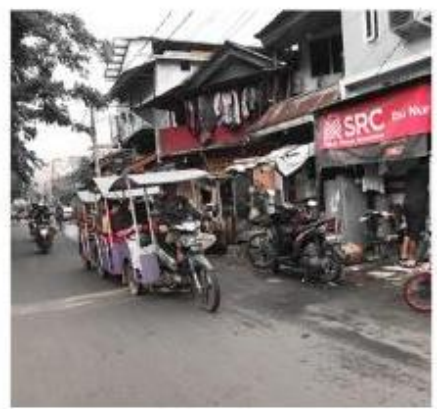

BERMAIN

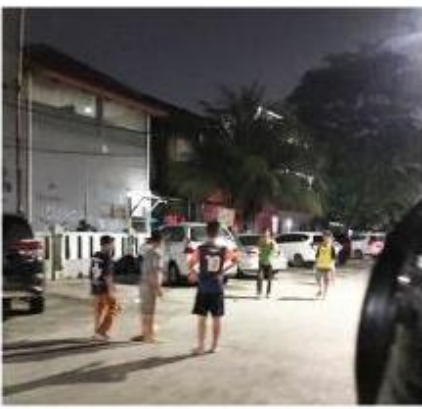

BEROLAHRAGA

Gambar 4. Diagram Aktivitas Masyarakat di Rawa Bunga Sumber: penulis, 2020

Program utama dipilih dari tema yaitu olahraga yang digabungkan dengan teknologi interaktif yang dapat membantu proses sosialisasi dan bermain sesama masyarakat. Disamping program utama, program pendukung disusun untuk menunjang kegiatan dan kebutuhan masyarakat di Rawa Bunga. Selain sebagai penunjang, program pendukung juga bertujuan untuk mengenalkan kebudayaan betawi di Rawa Bunga dengan cara yang halus. Program pendukung 
tersebut adalah; cinema interaktif (nobar video betawi), kuliner betawi, area serbaguna, retail games dan pernak - pernik betawi, ruang gambar LED betawi, dan area pentas serba guna outdoor.

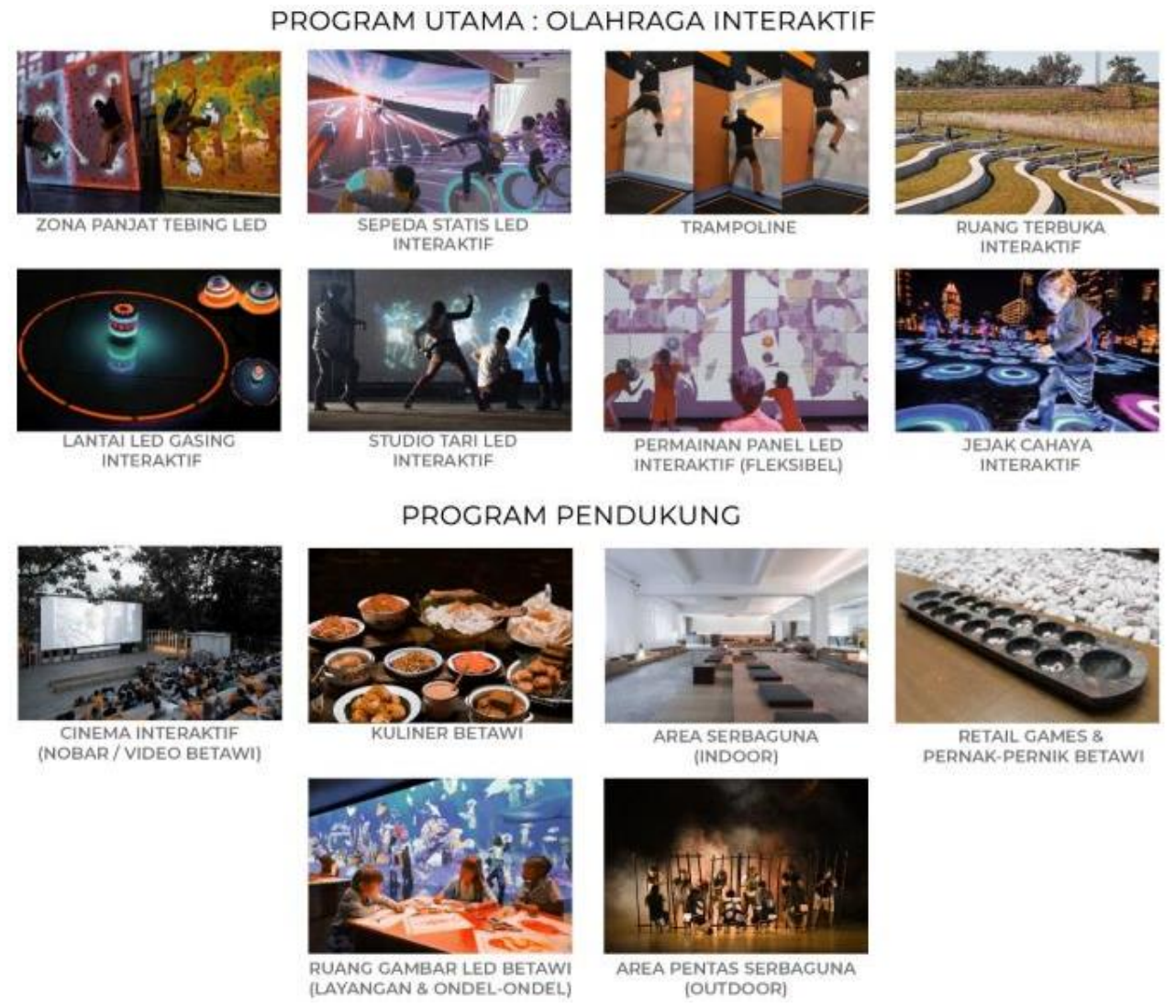

Gambar 5. Skema Program Utama dan Pendukung

Sumber: penulis, 2020

\section{Konsep Perancangan}

Konsep yang dipakai dalam perancangan proyek ini adalah dinamis. Sesuai dengan tema utama olahraga, dinamis berarti penuh semangat dan tenaga, atau sesuatu yang terus bergerak. Perancangan bangunan dari segi bentuk dan massing akan mengacu kepada konsep dinamis. Bentuk dinamis dapat diwujudkan dengan membuat tangga atau ramp yang dapat dinaiki sehingga membuat orang lebih aktif bergerak dan bisa dimanfaatkan sebagai ruang terbuka yang interaktif.
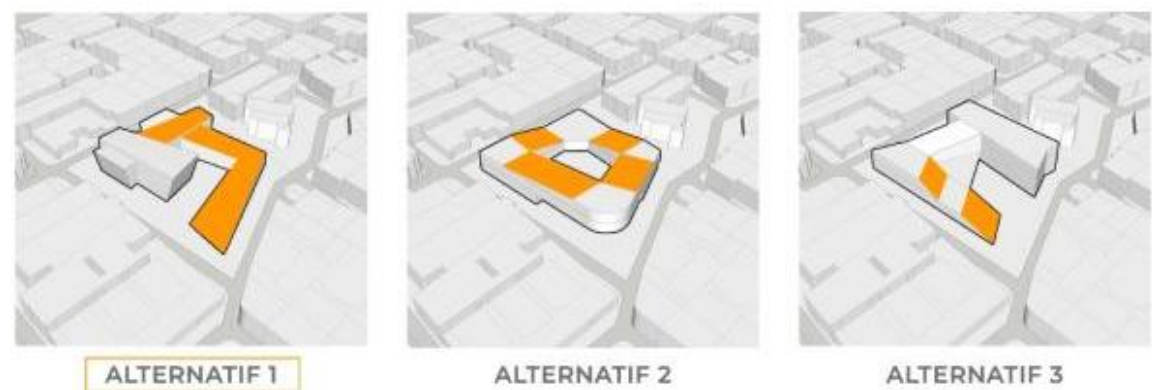

Gambar 6. Tiga Alternatif Massing Bangunan Sumber: penulis, 2020

Alternatif pertama dikembangkan lebih lanjut karena dinilai paling berkorelasi dengan konsep yang dinamis dan sesuai dengan potensi tapak yang ada. Pengembangan massing lebih lanjut 
dilakukan dengan menambahkan shading dan bukaan - bukaan yang sesuai dengan potensi dan kondisi tapak. Berikut adalah proses transformasi massing terpilih;

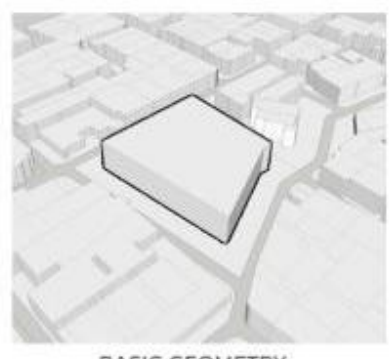

BASIC GEOMETRY
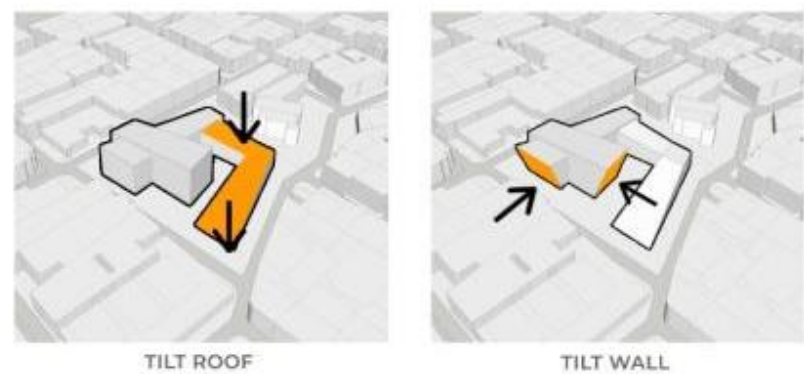

TILT WALL
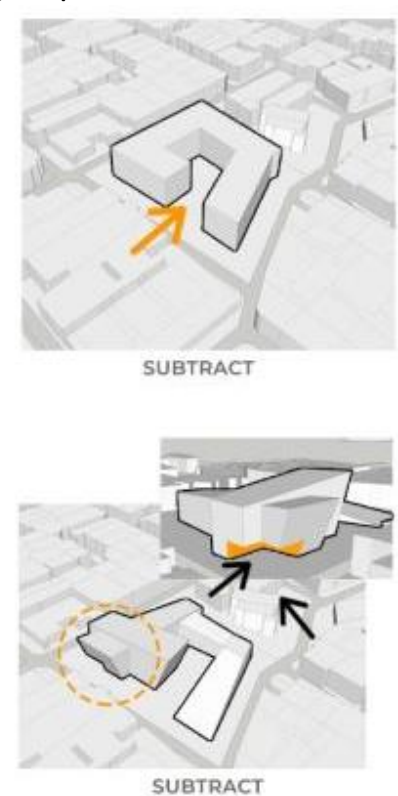

Gambar 7. Proses Transformasi Massing Bangunan

Sumber: penulis, 2020

\section{Hasil Perancangan}

Hasil perancangan berupa "Fasilitas Olahraga Interaktif di Rawa Bunga" yang merupakan third place yang bertujuan memenuhi kebutuhan masyarakat dan menyelesaikan masalah kebutuhan dasar manusia yang tidak terpenuhi di Rawa Bunga dan ditambah dengan mengenalkan genius loci kebudayaan betawi kepada masyarakat di Rawa Bunga.

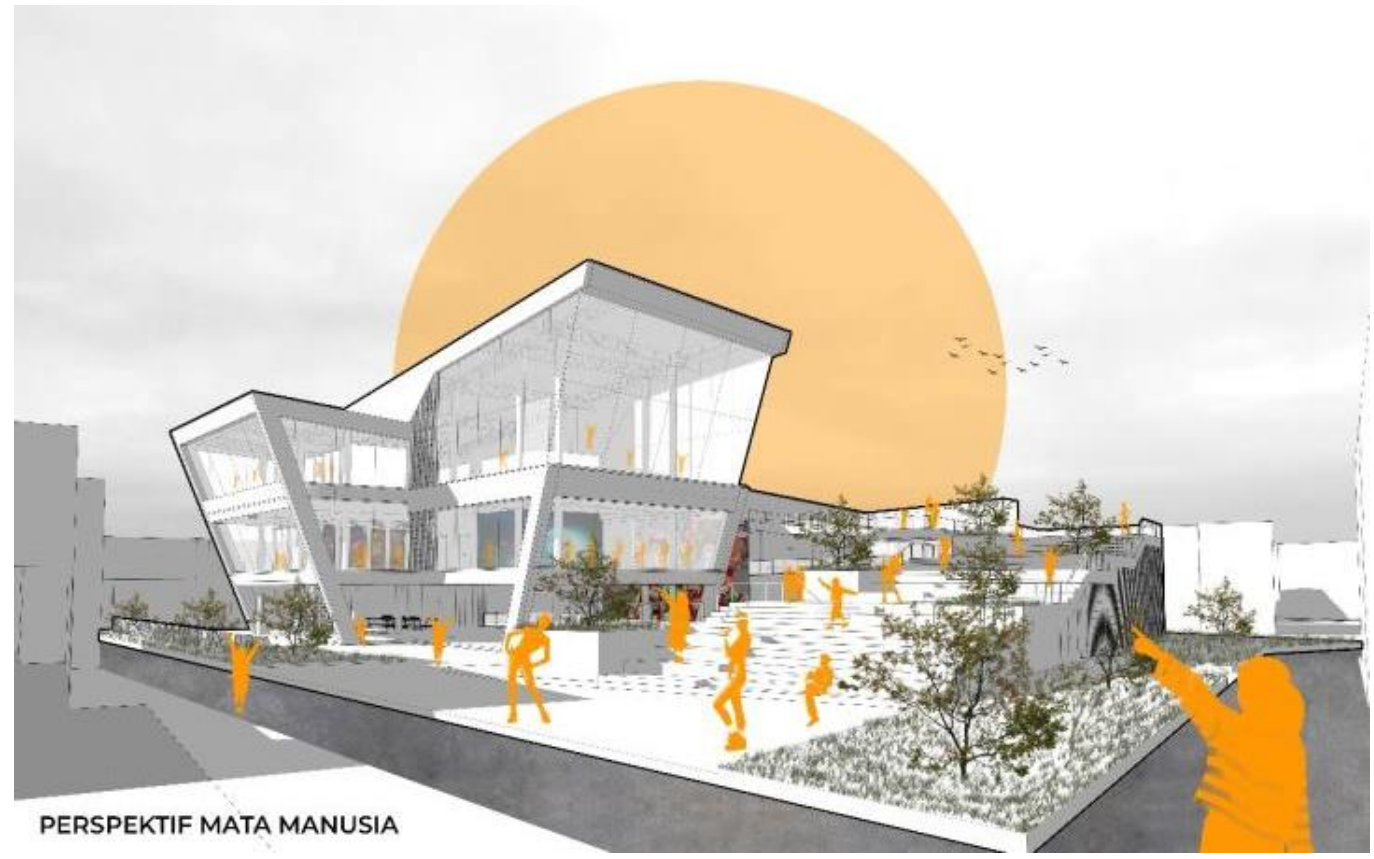

Gambar 8. Perspektif Mata Manusia Fasilitas Olahraga Interaktif di Rawa Bunga Sumber: penulis, 2020

Bentuk bangunan bersifat modern, hal ini bisa dilihat dari sistem kolom pilotis, façade yang terbebas dari struktur bangunan, dan desain jendela yang besar serta adanya rooftop garden 
pada bangunan. Penggunaan warna merah pada bangunan didasari oleh psikologi warna untuk memberi kesan dinamis, energik, dan aktif.

Sesuai dengan konsep yang digunakan bangunan memiliki entrance dari 3 sisi bangunan, hal ini memungkinkan terjadinya perembesan pergerakan manusia dari 3 arah dan meningkatkan aktivitas yang terjadi di bangunan. Pengunjung akan bisa menikmati stall makanan betawi, retail mainan dan pernak pernik budaya Betawi, lantai LED gasing, area serbaguna, dan ampiteater di lantai pertama bangunan. Pada lantai kedua, terdapat sepeda statis LED, loker, area game LED interaktif, dan juga studio tari beserta ruang ganti. Lantai ketiga dari bangunan memiliki zona trampoline yang terdiri atas area free jumping, zona basket, foam pit, dan juga panjat tebing LED. Servis dan pengelola pada bangunan ini lebih banyak ditempatkan di lantai dasar dan basement agar bisa memudahkan maintenance dan pergerakan tanpa mengganggu pengunjung yang datang.

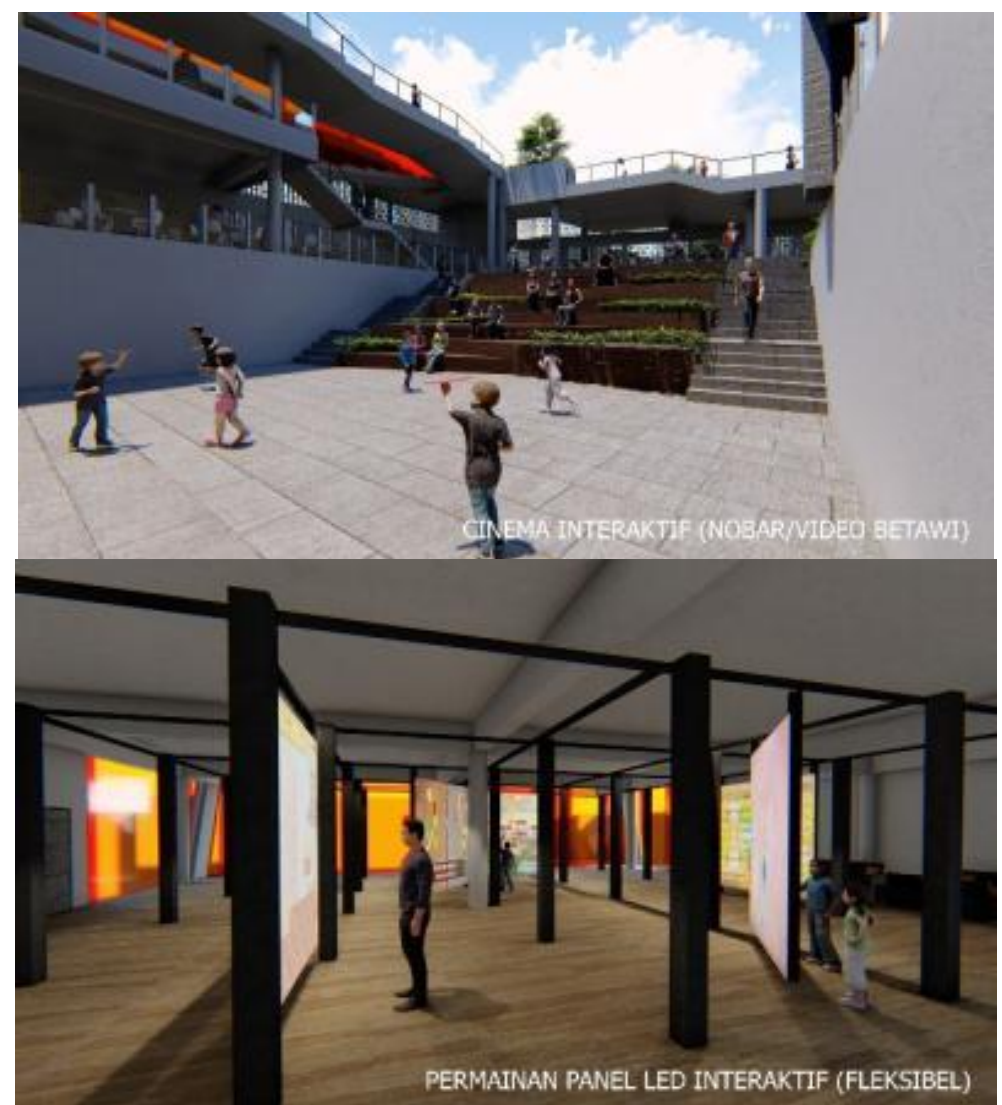

Gambar 9. Perspektif Interior Fasilitas Olahraga Interaktif di Rawa Bunga Sumber: penulis, 2020

\section{KESIMPULAN DAN SARAN}

\section{Kesimpulan}

Kesimpulan dari perancangan Fasilitas Olahraga Interaktif di Rawa Bunga adalah third place yang baik merupakan wadah yang sesuai dengan masyarakat yang dapat menjadi jawaban atas masalah yang terjadi di suatu Kawasan. Hal ini tentu didukung oleh rancangan third place yang memakai solusi berupa program dan kegunaan dari third place yang dirancang. Terlebih lagi, third place harus disesuaikan dengan keadaan dan genius loci yang ada di wilayahnya. Dalam perancangan Fasilitas Olahraga Interaktif di Rawa Bunga, third place dirancang untuk menjadi wadah masyarakat rawa bunga yang menyelesaikan masalah kebutuhan dasar manusia di Rawa Bunga lewat program olahraga interaktif yang digemari masyarakat dalam kebiasaan sehari - hari dan berusaha mengaktivasi citra Betawi yang aktif pada masyarakatnya. 


\section{Saran}

Saran yang bisa dibagikan adalah pemerintah Jakarta harus bisa mendata jumlah kenaikan penduduk di seluruh kawasan dan juga pertumbuhan dari penduduknya. Dengan data tersebut, maka pemerintah akan bisa beradaptasi dengan pertumbuhan kebutuhan yang terjadi akibat bertambahnya penduduk. Usaha pemerintah bisa berupa memberikan fasilitas lingkungan yang memadai untuk masyarakat.

\section{REFERENS}

De Botton, A. (2006). The Architecture of Happiness. Vintage Books.

Latif, F. (2019). Statistik Daerah Kota Jakarta Timur 2019. BPS Kota Jakarta Timur. Maslow, A. (1943). A Theory of Human Motivation. Wilder Publications, Inc.

Oldenburg, R. (1999). The Great Good Place. Da Capo Press.

Rambe, B. (2019). Jatinegara Dalam Angka 2019. BPS Kota Jakarta Timur.

Sparacino, F. (2004). Narrative Spaces: Bridging Architecture and Entertainment Via Interactive Technology. International Conference on Generative Art.

Warsita, B. (2008). Teknologi Pembelajaran: Landasan \&Aplikasinya. Rineka. 